\title{
Assessment Model and Virtual Simulation for Fatigue Damage Evolution of Asphalt Mortar and Mixture
}

\author{
Danhua Wang, ${ }^{1}$ Xunhao Ding $\mathbb{D}^{2},{ }^{2}$ Linhao Gu, ${ }^{2}$ and Tao Ma $\mathbb{D}^{2}$ \\ ${ }^{1}$ School of Computer Engineering, Nanjing Institute of Technology, 1 Hongjin Road, Nanjing, Jiangsu 211167, China \\ ${ }^{2}$ School of Transportation, Southeast University, 2 Sipailou, Nanjing, Jiangsu 210096, China \\ Correspondence should be addressed to Tao Ma; matao@seu.edu.cn
}

Received 26 October 2018; Accepted 22 November 2018; Published 9 December 2018

Guest Editor: Quantao Liu

Copyright (C) 2018 Danhua Wang et al. This is an open access article distributed under the Creative Commons Attribution License, which permits unrestricted use, distribution, and reproduction in any medium, provided the original work is properly cited.

Focused on the fatigue performance of the asphalt mortar, this study proposed an assessment model for fatigue damage evolution based on the continuum mechanics. From the perspective of the material scale rather than the macrostructure, the proposed damage model was set by concentrating on the stress-strain state of a tiny point which could characterize the material performance accurately. By the mechanical formula derivation and based on the four-point bending fatigue tests, the damage evolution law was determined and then the proposed model was verified. Based on the finite element method (FEM), a commercial software named ABAQUS was utilized to develop the random mixtures consisting of coarse aggregates, mortar, and voids. Eventually, combined with the damage model and virtual simulation of bending tests, the factors influencing the fatigue resistance of the whole asphalt mixtures were analyzed further.

\section{Introduction}

Asphalt mixture is a three-phase structure consisting of aggregate, void, and mortar [1-3]. The asphalt mortar, acting as a bonding layer between adjacent particles, has been highlighted by many researchers to play an important role in the performance of the whole mixtures $[4,5]$. Different form the mixtures, the asphalt mortar consists of the binder, mineral powder, and the fine aggregates only.

Tests conducted by Tan et al. [6] have pointed out that the fine aggregate properties play an important role in the viscoelastic performance of the asphalt mortar. To obtain better viscous properties and low-temperature performance, abundant angular fine aggregates are necessary. Hasan et al. [7] designed and carried out the creep tests of the asphalt mortar. In their tests, four kinds of binder were used including one base binder and three modified ones. It is found that the test environmental temperature along with the binder types all affected the occurrence of the mortar creep in porous asphalt. Permeability loss was more significant when the base binder was used. Wang et al. [8] utilized the rolling thin film oven to reveal the influence of mineral powder on the aging characters of asphalt mortar.
The results showed that when the mass ratio of mineral powder to mortar was less than 1.5 , the mineral powder contents had a positive effect on asphalt aging; when the mass ratio of mineral powder to mortar was more than 1.5 , increasing the contents of mineral powder could only accelerate asphalt aging. Thus, it is necessary to determine the best ratio of mineral powder during pavement construction. Similar findings have been put forward by many others showing the mortar effects in the whole mixtures [9-11].

Apart from the research studies based on the laboratory tests, many numerical methods such as discrete element method (DEM) and finite element method (FEM) were introduced to illustrate the mechanical behavior of the asphalt mortar. These computational techniques accelerate the related studies and reveal the materials' mechanism from a new perspective [12-15]. Based on these numerical methods, many researchers have done virtual tests to evaluate the performance of the asphalt mortar and concluded some meaningful findings [16-18].

In the road engineering, the main concern is about how to evaluate the fatigue properties of the materials and establish the corresponding mathematical model to predict the 
long-term performance of the pavement structure. These fatigue damage evolution models were necessary guarantees for the precise simulations. Only by importing the model into numerical simulation firstly, the outputs from the numerical software can be convinced and valuable. To reveal the long-term behavior of pavements under cyclic vehicle load, many researchers proposed their own damage models [19-23]. However, most of the proposed damage evolution models were developed from the macrostructure scale and could only predict the behavior of the designed composition and structures. The methods characterizing the damage evolution from the material scale still need to be further studied, especially for the asphalt mortal in the road field.

\section{Objective and Scope}

The objective of this study is to establish the fatigue damage evolution model for the asphalt mortar. It is for the mortar material rather than the test structures. To achieve this, the four-point bending fatigue tests and the FEM simulation were utilized together. Prior to processing, several assumptions were made as follows:

(1) The macrofracture of the aggregate, mortar, and mixtures was not included here, and only the damage evolution was taken into considerations. The damage and fracture are two different stages for the materials [24]. This helps to determine the study scope of this paper, and the damage evolution of the materials was concentrated on only here.

(2) The damage of the asphalt mortar dominated within the whole mixtures while the coarse aggregates were regarded as the variation of the boundary conditions. It is believed that the damage mainly occurs within the asphalt mortar rather than the aggregates. Because the properties of aggregates are not changed mostly under the cyclic loading, few of the particles will break. Oppositely, the interfaces between aggregates and mortar and the inner area of the mortar tend to generate microcracks more easily which leads to a performance decline. And this is the main cause of the fatigue damage. So, the damage of the asphalt mortar rather than the mixtures was studied here.

(3) Due to the low temperature of the designed tests, the viscoelastic characteristics of asphalt mixtures could be neglected temporary, and the mixtures were regarded as elastic materials [25]. Thus, the fatigue damage evolution models of the asphalt mortar could be derived based on the linear elastic theory.

The rest of this paper is organized as follows. Section 3 mainly introduces the materials, apparatus, simulation methods, and the derivation of the fatigue damage evolution formulas. In Section 4, the damage evolution law and the major factors on the damage process are analyzed based on the laboratory tests. Moreover, the validation of the proposed model is verified and is applied within the FEM simulation to predict structure performance further. Finally, some research findings are summarized in Section 5.

\section{Methodology and Experimental}

3.1. Materials. The asphalt binder, mineral powder, and aggregates were prepared for this study. Prior to laboratory tests, the base properties of materials were measured firstly to meet the requirements of the Chinese Technical Specification for Construction of Highway Asphalt Pavement [26]. The summaries of the material properties are shown in Tables 1-3. Two types of the specimens are needed in the following process: (a) asphalt mixtures consisting of asphalt binder, mineral powder, and aggregates and (b) asphalt mortar consisting of asphalt binder, mineral powder, and the fine part of aggregates. The testing gradation of the asphalt mixture is shown in Figure 1(a) meeting the requirements of Chinese standard [26]. Since the aggregates smaller than $2.36 \mathrm{~mm}$ are regarded as part of asphalt mortar, the specific content of the fine aggregates within mortar can be determined based on the mixture gradation as shown in Figure 1(b). This recalculation of the mortar gradation is necessary to keep the other compositions same as the prepared mixtures. Only the coarse aggregates should be extracted.

3.2. Laboratory Test. According to the Chinese specification named Standard Test Methods of Bitumen and Bituminous Mixtures for Highway Engineering (T07392011) [27], the four-point bending beam fatigue tests based on the universal testing machine (UTM) were selected to evaluate the fatigue performance of the asphalt mortar and asphalt mixture. The fatigue tests of asphalt mortar were used to obtain model parameters and to study the influencing factors of fatigue performance. Three major factors were taken into consideration and varied during the test process, including the test temperature $\left(5^{\circ} \mathrm{C}\right.$ and $\left.10^{\circ} \mathrm{C}\right)$, loading strain $(700 \mu \varepsilon$ and $1000 \mu \varepsilon)$, and the asphalt content of mortar $(4.3 \%, 4.8 \%$, and $5.5 \%)$. Hereafter, in this study, the asphalt content of $4.3 \%, 4.8 \%$, and $5.5 \%$ was referred to as low, moderate, and high contents, respectively. One fatigue test of asphalt mixture under the condition of $5^{\circ} \mathrm{C}, 700 \mu \varepsilon$ and moderate asphalt content was conducted. The test data were used to verify the FE model of asphalt mixture. The tests were conducted strictly according to the Chinese standard [27], and the bending stiffness modulus was calculated as shown in equations (1)-(3). A load with haversine amplitude is applied to simulate the strain-control loading condition $(10 \mathrm{~Hz})$. The fatigue life was defined as the load cycles when the bending stiffness modulus decreased to $50 \%$ compared to the initial one:

$$
\sigma_{\mathrm{t}}=\frac{(L \times P)}{\left(w \times h^{2}\right)},
$$

where $\sigma_{\mathrm{t}}$ is the maximum tensile stress of the centre bottom of the test beam, Pa; $L$ is the length of the test beam, m; $P$ is 
TABLE 1: Base properties of asphalt binder.

\begin{tabular}{lcc}
\hline Index & Results & Requirements \\
\hline Penetration $\left(25^{\circ} \mathrm{C}, 100 \mathrm{~g}, 5 \mathrm{~s}\right) / 0.1 \mathrm{~mm}$ & 71 & $60-80$ \\
Ductility $\left(10^{\circ} \mathrm{C}\right) / \mathrm{cm}$ & 31.3 & $\geq 20$ \\
Softening point $\left({ }^{\circ} \mathrm{C}\right)$ & 48.2 & $\geq 46$ \\
Flash point $\left({ }^{\circ} \mathrm{C}\right)$ & 287 & 260 \\
Density $\left(\mathrm{g} / \mathrm{cm}^{3}\right)$ & 1.031 & - \\
\hline
\end{tabular}

TABle 2: Base properties of mineral powder.

\begin{tabular}{lccc}
\hline Index & & Results & Requirements \\
\hline & $<0.6 \mathrm{~mm}$ & 100 & 100 \\
Granularity (\%) & $<0.15 \mathrm{~mm}$ & 96.5 & $90-100$ \\
& $<0.075 \mathrm{~mm}$ & 85.3 & $75-100$ \\
\hline
\end{tabular}

peak load during test, $\mathrm{N} ; w$ is the width of the test beam, m; and $h$ is the height of the test beam, m.

$$
\varepsilon_{\mathrm{t}}=\frac{(12 \times \delta \times h)}{\left(3 \times L^{2}-4 \times a^{2}\right)},
$$

where $\varepsilon_{\mathrm{t}}$ is the maximum tensile strain of the centre bottom of the test beam, $\mathrm{m} / \mathrm{m} ; \delta$ is the maximum deflection of the beam centre, $\mathrm{m}$; and $a$ is the spacing distance between two adjacent chucks.

The bending stiffness modulus was defined as follows:

$$
S=\frac{\sigma_{\mathrm{t}}}{\varepsilon_{\mathrm{t}}}
$$

where $S$ is the bending stiffness modulus, $\mathrm{Pa}$; $\sigma_{\mathrm{t}}$ is the maximum tensile stress of the centre bottom of the test beam, $\mathrm{Pa}$; and $\varepsilon_{\mathrm{t}}$ is the maximum tensile strain of the centre bottom of the test beam, $\mathrm{m} / \mathrm{m}$.

The damage of the centre bottom of the test beam at the Nth load cycle was calculated as follows:

$$
D_{N}=1-\frac{S_{N}}{S_{0}}
$$

where $D_{N}$ is the damage at the $N$ th load cycle; $S_{N}$ is the bending stiffness modulus at the $N$ th load cycle, $\mathrm{Pa}$; and $S_{0}$ is the initial bending stiffness modulus, which is the bending stiffness modulus at the 50th load cycle according to the Chinese specification [27].

\subsection{Fatigue Damage Model Development for Asphalt Mortar.} As a design index according to the Chinese standard [26], the requirement of the tensile strain in the layer bottom is much more significant to ensure fatigue resistance. Thus, only focused on the tensile damage, which dominated within the pavement structure under the cyclic load, the tensile damage evolution model was proposed to characterize the mixture performance. Since the bending stiffness modulus (S) obtained from the tests can only represent the structure performance, it is a macroindex characterizing the whole beam rather than materials. Thus, the fatigue damage model was developed further. Based on the principle of the continuum mechanics, when all the external load, boundary conditions, and structure size are determined, the stress-strain state of point $\mathrm{C}$ can be obtained obviously. By establishing the mathematic relation of damage between the beam structure and centre bottom point, the damage evolution model of a tiny point can be obtained. And this point damage model is regarded as the micromaterial properties under the cyclic load regardless of the macrostructures. The details of the fatigue damage model are shown in Figure 2.

$D_{\mathfrak{c}}, \varepsilon_{\mathfrak{c}}$, and $\sigma_{\mathfrak{c}}$ are defined as the damage, strain, and stress of point $C$ after $N$ times cyclic load, while the $D, \varepsilon$, and $\sigma$ are the damage, strain, and stress of random points in the cross section of the beam after $N$ times cyclic load. The constitutive model and fatigue damage evolution model are developed as an initial form as shown in equations (5) and (6).

The constitutive model:

$$
\sigma=(1-D) E \mathcal{\varepsilon} .
$$

The fatigue damage evolution model:

$$
\frac{d D}{d N}=A[\varepsilon(1-D)]^{p},
$$

where $E$ is the elastic modulus and $A$ and $p$ are the coefficients to be determined, related to the material properties.

When derived the evolution formulas for mortar, the mortar was assumed as an isotropic continuum medium. So the four-point bending fatigue test for mortar could be regarded as a plane stress problem. The stress and strain vertical to the cross section were selected for formula derivation then. For random points in the cross section of the beam, equilibrium condition should be reached at any time, and then equations (8) and (9) can be obtained as follows:

$$
\begin{aligned}
\int_{0}^{1} \sigma w h d \lambda & =0, \\
\int_{0}^{1} \sigma w h^{2} \lambda d \lambda & =M, \\
\lambda & =\frac{y}{h},
\end{aligned}
$$

where $\lambda$ is the relative position of random points along the Y-coordinates direction; $y$ is the Y-coordinates of the random points; $M$ is the bending moment of the cross section of the beam, N.m; and the other parameters are the same as the formers.

Since the cyclic load, more microcracks and microholes will appear during the process especially in the centre bottom area of the beam. This causes damage and will make the neutral axis move upwards gradually. Thus, $\lambda_{N}$ is proposed and defined as the new position of the neutral axis after $N$ times cyclic load as follows:

$$
\lambda_{n}=\frac{y_{n}}{h},
$$

where $\lambda_{n}$ is the relative position of neutral axis along the Y-coordinates direction after $N$ times cyclic load; $y_{n}$ is the 
TABLE 3: Base properties of aggregates.

\begin{tabular}{|c|c|c|c|c|c|c|}
\hline \multicolumn{7}{|l|}{ Coarse part } \\
\hline Size $(\mathrm{mm})$ & $16-13.2$ & \multicolumn{2}{|c|}{$13.2-9.5$} & \multicolumn{2}{|c|}{$9.5-4.75$} & $4.75-2.36$ \\
\hline Density $\left(\mathrm{g} / \mathrm{cm}^{3}\right)$ & 2.771 & \multicolumn{2}{|c|}{2.791} & \multicolumn{2}{|c|}{2.688} & 2.735 \\
\hline \multicolumn{7}{|l|}{ Fine part } \\
\hline Size $(\mathrm{mm})$ & $2.36-1.18$ & $1.18-0.6$ & $0.6-0.3$ & $0.3-0.15$ & $0.15-0.075$ & $<0.075$ \\
\hline Density $\left(\mathrm{g} / \mathrm{cm}^{3}\right)$ & 2.715 & 2.718 & 2.716 & 2.717 & 2.720 & 2.752 \\
\hline
\end{tabular}

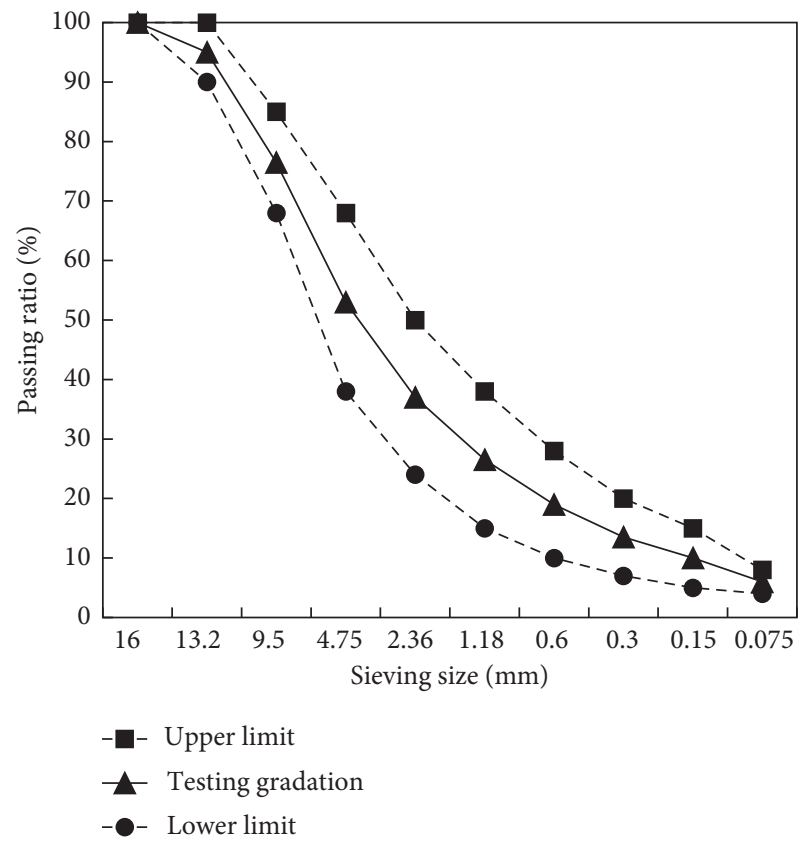

(a)

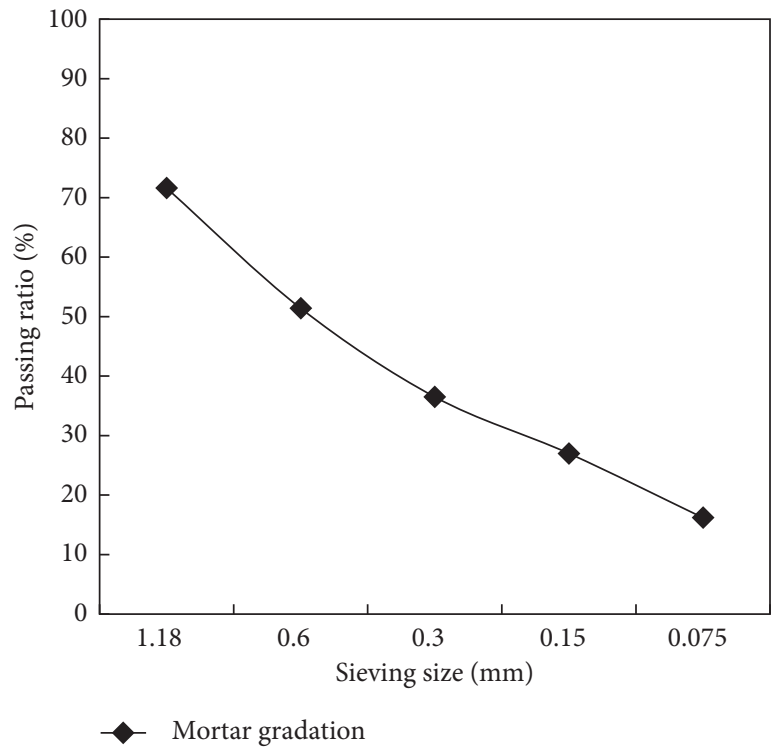

(b)

FIGURE 1: Testing gradations: (a) gradations for the asphalt mixtures; (b) gradations for the asphalt mortar.

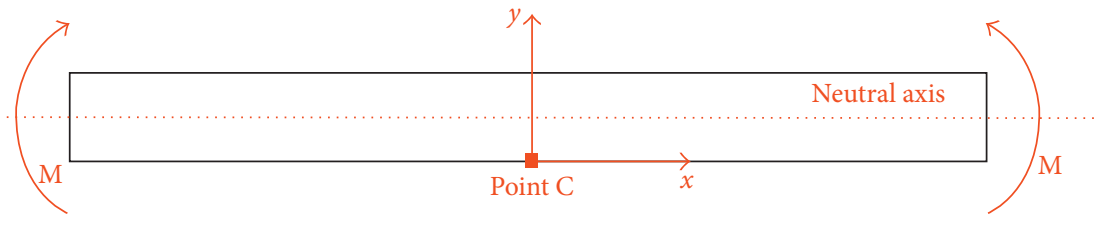

Figure 2: Fatigue damage of the point C.

Y- coordinates of the neutral axis after $N$ times cyclic load, $\mathrm{m}$; and the other parameters are the same as the formers.

Substituting equation (5) into equations (8) and (9), we obtain

$$
\begin{gathered}
\int_{0}^{\lambda_{n}} w h E(1-D) \varepsilon d \lambda+\int_{\lambda_{n}}^{1} w h E \varepsilon d \lambda=0, \\
\int_{0}^{\lambda_{n}} w h^{2} E(1-D) \varepsilon \lambda d \lambda+\int_{\lambda_{n}}^{1} w h^{2} E \varepsilon \lambda d \lambda=M,
\end{gathered}
$$

where the parameters are the same as the formers.

In the strain control mode, the strain of the centre bottom of the beam remains the same; thus, we obtain

$$
\varepsilon=\frac{y}{\rho}
$$

where $\rho$ is the curvature of the beam.

Defining $\eta=\left(\lambda_{n}-\lambda\right) / \lambda_{n}$ and substituting it into equation (12), the strain of random points can be obtained as follows:

$$
\begin{gathered}
\varepsilon=\varepsilon_{c} \eta, \\
d \lambda=-\lambda_{n} d \eta .
\end{gathered}
$$

Substituting equations (13) and (14) into (9), we obtain

$$
\int_{0}^{1} \eta D d \eta=\frac{1}{\lambda_{n}}-\frac{1}{2 \lambda_{n}^{2}}
$$

$$
\int_{0}^{1} \eta\left[\int_{0}^{N}\left(\frac{d D}{d N}\right) d N\right] d \eta=\frac{1}{\lambda_{n}}-\frac{1}{2 \lambda_{n}^{2}} .
$$


Taking equation (6) into (16), we obtain

$$
\int_{0}^{N} A[\varepsilon(1-D)]^{p} d N=2\left(\frac{1}{\lambda_{n}}-\frac{1}{2 \lambda_{n}^{2}}\right) .
$$

To the point $\mathrm{C}, \lambda=0$, combined with the equation (6), we obtain

$$
\int_{0}^{N} A\left[\varepsilon_{\mathrm{c}}\left(1-D_{\mathrm{c}}\right)\right]^{p} d N=D_{\mathrm{c}}
$$

The damage of the point $\mathrm{C}$ can be determined through equations (17) and (18) as follows:

$$
D_{c}=2\left(\frac{1}{\lambda_{n}}-\frac{1}{2 \lambda_{n}^{2}}\right) \text {. }
$$

The unknown parameter $\lambda_{n}$ can be solved through equation (19) as follows:

$$
\lambda_{n}=\frac{1}{1+\sqrt{1-D_{c}}} .
$$

Apply the integral operation on both sides of equation (6), the fatigue damage evolution model for each point can be developed as shown in equation (21), and the Point $\mathrm{C}$ is shown in equation (22):

$$
\begin{gathered}
D=1-\left[1-(-p+1) A \varepsilon^{p} N\right]^{(1 /(-p+1))}, \\
D_{\mathrm{c}}=1-\left[1-(-p+1) A \varepsilon_{\mathrm{c}}^{p} N\right]^{(1 /(-p+1))} .
\end{gathered}
$$

3.4. FEM Modelling of Asphalt Mixture. Virtual models were developed based on the FEM software named ABAQUS. Two model forms were taken into consideration. One is the virtual asphalt mortar and another is the asphalt mixtures. The virtual four-point bending fatigue tests for mortar were carried out to verify the FEM implementation of the proposed fatigue damage model. After that, the precise damage model of the mortar was imported into the virtual mixtures, and the virtual four-point bending fatigue tests for mixture were conducted. The simulation results were compared with the laboratory results of asphalt mixture to verify the mesostructure FE model. More simulations were conducted to analyze the effect of air void on damage evolution.

The coarse aggregates were regarded as pure elastomer without any damage evolution. When conducted the virtual tests, Young's modulus and Poisson's ratio of the coarse aggregates were set as $5.55 \mathrm{GPa}$ and 0.15 , respectively. The virtual specimens were developed with a $377 \mathrm{~mm}$ length and $50 \mathrm{~mm}$ height in two dimensions, which were identical to the realistic. The final virtual specimens for asphalt mixture are shown in Figure 3(a). Free meshing algorithm with quaddominated element shape was used. And the type is CPS8R (an 8-node biquadratic plane stress quadrilateral, reduced integration). The green, white, and red areas represent aggregates, asphalt mortar, and air voids, respectively. Asphalt mortar was considered as an isotropic material, and its FE model is shown in Figure 3(b). Structured meshing algorithm with quad element shape was used. And the element type is also CPS8R.

As shown in Figure 3(c), the position of four virtual clamps was the same as the real test. Clamp C was fixed in all degrees of freedom. A vertical displacement boundary condition with haversine amplitude was applied to clamp A to simulate the strain-control loading condition $(10 \mathrm{~Hz}, 700 \mu \varepsilon$, and $1000 \mu \varepsilon$ ). The horizontal displacement and rotation of clamp A were constrained. The clamps were connected to the sample using surface-to-surface contact with geometric properties. The clamps were considered as pure elastomer with Young's modulus far greater than that of the sample.

The virtual mixtures including the asphalt mortar, irregular shape voids, and coarse aggregates were also developed in ABAQUS. Prior to FEM modelling, preprocessing for the random composition generations was completed based on Matlab. A user-defined routine was coded in Matlab to help develop the irregular shapes of particles and finally form the total mixtures as shown in Figures 4 and 5. As shown in Figure 4, polar coordinates were utilized in the irregular shapes plotting. Several groups of coordinate values were determined randomly within a designed range firstly and then a circumscribing polygon was plotted to form the final shapes. When developed the mixtures, particles of different grades were generated in turns based on their sizes. As shown in Figure 5, the rectangle was plotted as a virtual container, and then particles of $16 \mathrm{~mm}$ size were plotted firstly followed by $13.2 \mathrm{~mm}$, $9.5 \mathrm{~mm}, 4.75 \mathrm{~mm}$, etc. After the particle generations were completed, the voids were plotted in the same way. As shown, three kinds of mixtures were developed randomly. The blue lines represented the coarse aggregates while the red ones are the voids. The percent air voids in bituminous mixtures (VV) were $0 \%, 4 \%$, and $8 \%$, and the percent voids in mineral aggregate in bituminous mixtures (VCA) were $32.3 \%, 32.1 \%$, and $30.7 \%$, respectively. It should be noted that when plotted the irregular shapes of particles and voids, a judgment routine was conducted in Matlab to avoid the shape overlaps. If there existed a particle or void already, the next particle or void generation would not be permitted here until another available location was found. After the mixture images were generated successfully finally, they were imported to ABAQUS for structure and mesh generations as shown in Figure 6.

3.5. Model Parameter Determination of the Asphalt Mortar. Since the damage evolution of the asphalt mortar dominates within the whole mixtures, its model should be further specified by determining the related parameters. As illustrated in equation (22), the fatigue damage variable is related to two material parameters $(A$ and $p)$. A nonlinear minimization algorithm using differential evolution method is performed on the target error function $F$ as

$$
\min F(A, p)=\frac{1}{N} \sqrt{\sum_{i=1}^{N}\left(1-\frac{D_{\mathrm{c}, i}}{D_{\mathrm{t}, i}}\right)^{2}},
$$




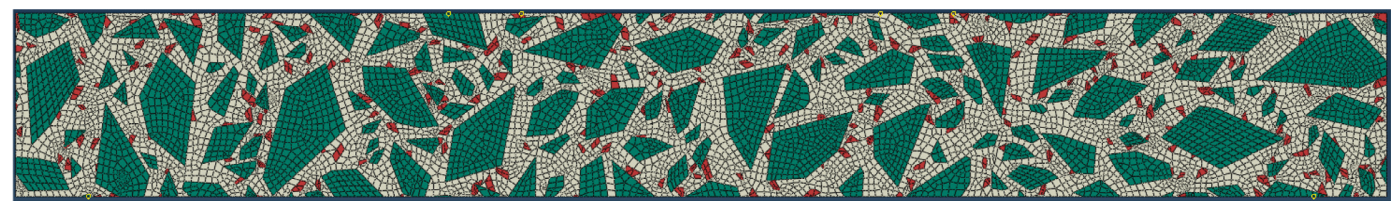

(a)

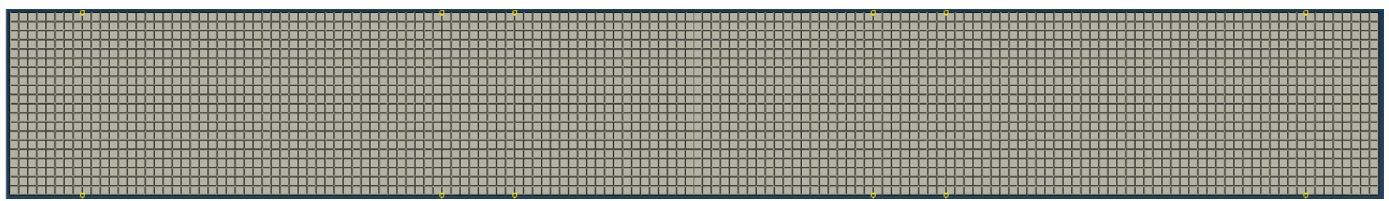

(b)

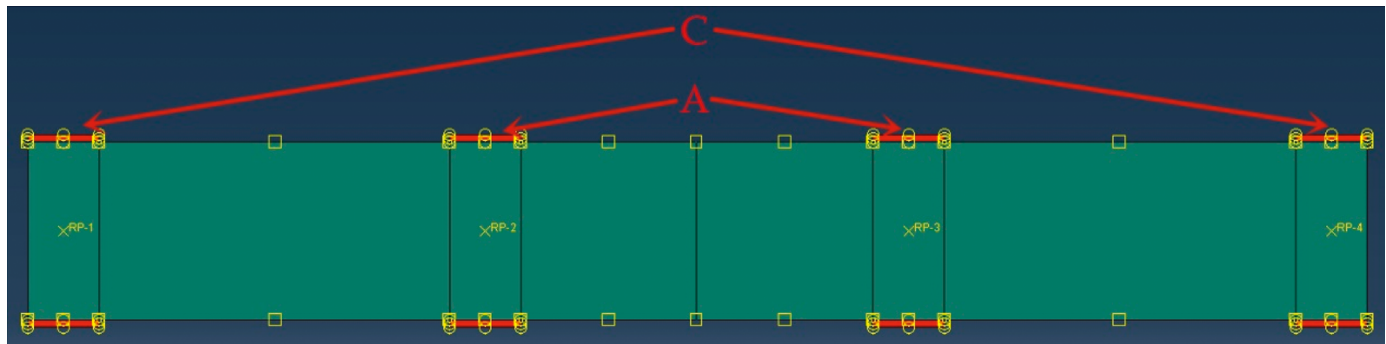

(c)

FIGURE 3: FEM modelling: (a) asphalt mixture sample; (b) asphalt mortar; (c) clamps.

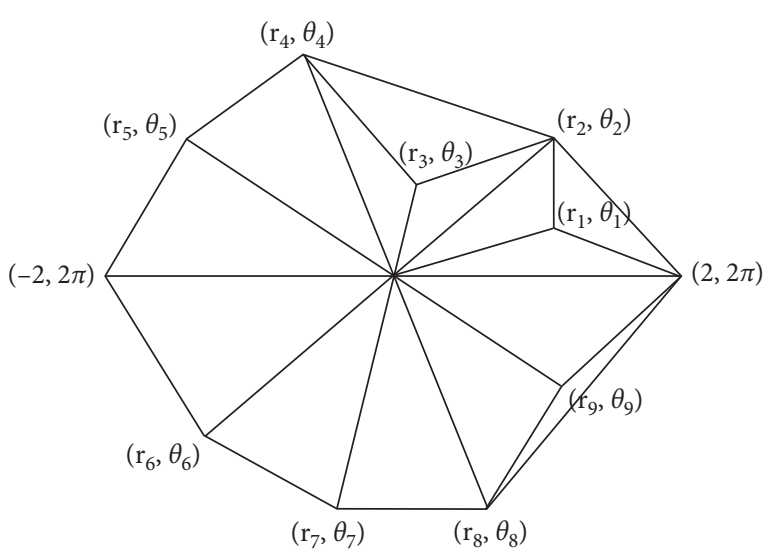

FIGURE 4: Irregular shape modelling for particles.

where $D_{c, i}$ is the calculated damage and $D_{t, i}$ is the damage obtained from laboratory results using equation (4).

By fitting the laboratory results, these undetermined parameters could be confirmed. Figures 7 and 8 are the fitting results of the proposed fatigue damage evolution models. Different conditions including the temperature, loading strain, and asphalt content were taken into considerations. The values of $A$ and $p$ applied for these conditions are all calibrated and summarized in Table 4. As shown in Figures 7 and 8, it is concluded that the proposed damage model could well characterize the fatigue performance of the asphalt mortar in the first two stages. In the third stage, the damage evolved rapidly converting the inner microcracks into macrofracture. In this stage, the macrocracks dominated, and therefore the modulus of the structure decreased sharply. Thus, focusing on the damage evolution only without the macrofracture mechanism, the fitting lines could only characterize the first two stages. And it has been verified in Figures 7 and 8 that the proposed damage evolution models could well predict the performance of asphalt mortar before fracture.

\section{Results and Discussion}

4.1. Analysis of the Laboratory Fatigue Tests. The results of the four-point bending fatigue tests in laboratory are summarized in Figures 9 and 10. Figure 9 illustrates the influences of the temperatures and strain levels on the fatigue performance of asphalt mortar. As shown in Figure 9, when compared the curves of $5^{\circ} \mathrm{C}, 700 \mu \varepsilon$ with the $5^{\circ} \mathrm{C}, 1000 \mu \varepsilon$ in Figures 9(a)-9(c), it is concluded that the strain level has a negative effect on the changes of the bending stiffness modulus (S). When comes to the curves of $5^{\circ} \mathrm{C}, 1000 \mu \varepsilon$ and $10^{\circ} \mathrm{C}, 1000 \mu \varepsilon$, it is found that as the temperature increases, the asphalt mortar will have better fatigue resistances. Moreover, the strain level plays a much more important role than temperature in affecting the fatigue performance of asphalt mortar which can be obviously summarized from Figure 9. The fatigue lives of $5^{\circ} \mathrm{C}, 700 \mu \varepsilon$ are much more than the $10^{\circ} \mathrm{C}, 1000 \mu \varepsilon$ despite the asphalt content. It is believed that the load strain decreased by $300 \mu \varepsilon$ has a more positive effect than increasing the temperature by $5^{\circ} \mathrm{C}$. Thus, avoiding the heavy traffic is significant to maintain the pavement permanent performance. As for Figure 9(c), different trends could be also found that the bending stiffness modulus $(\mathrm{S})$ of the $5^{\circ} \mathrm{C}$, $1000 \mu \varepsilon$ was a litter larger than the other two at high asphalt contents. This is because of the lowest temperature and largest strain level which are the worst conditions for the mortar. When the asphalt content is high, the lower 


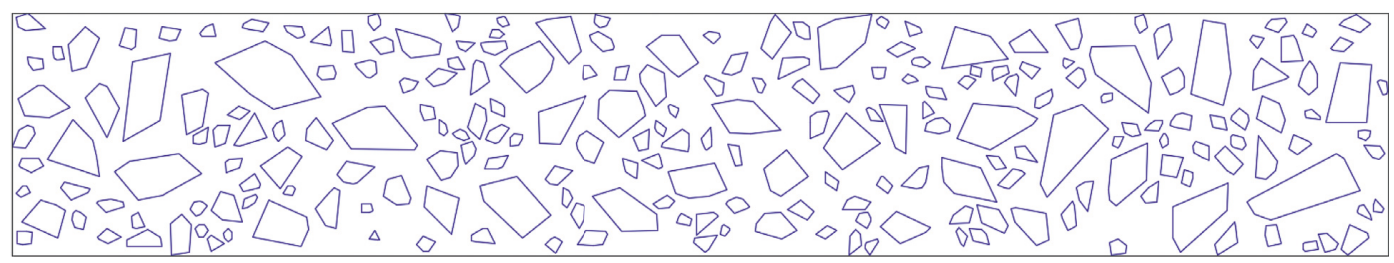

(a)

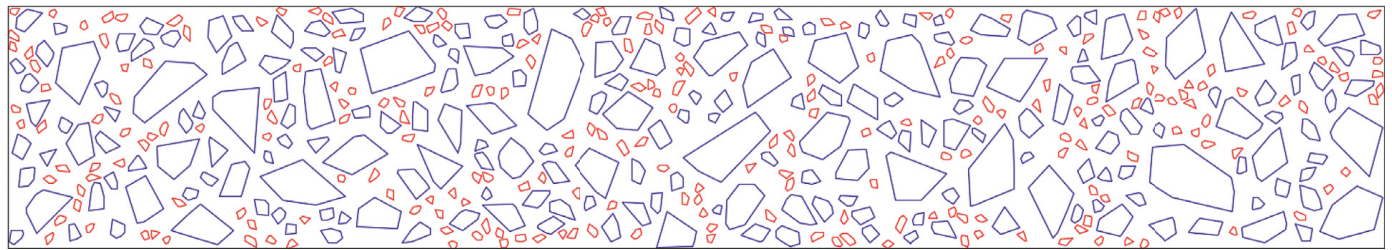

(b)

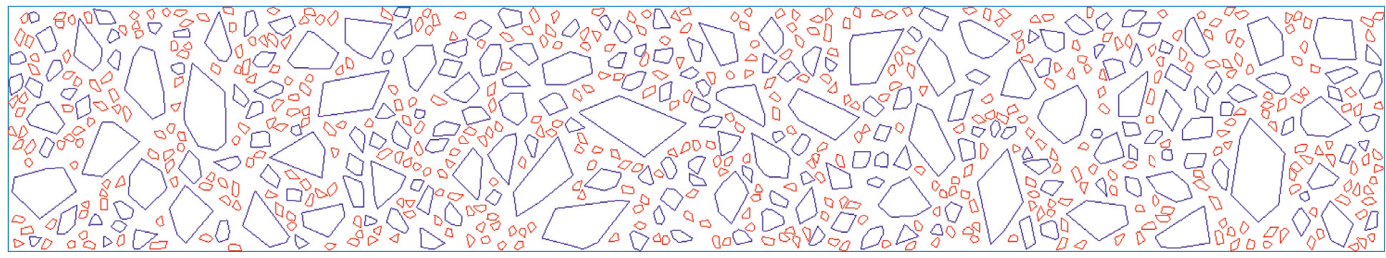

(c)

Figure 5: Irregular shape modelling for mixtures: (a) VCA $=32.3 \%, \mathrm{VV}=0 \%$; (b) VCA $=32.1 \%, \mathrm{VV}=4 \%$; $(\mathrm{c}) \mathrm{VCA}=30.7 \%$, VV $=8 \%$.

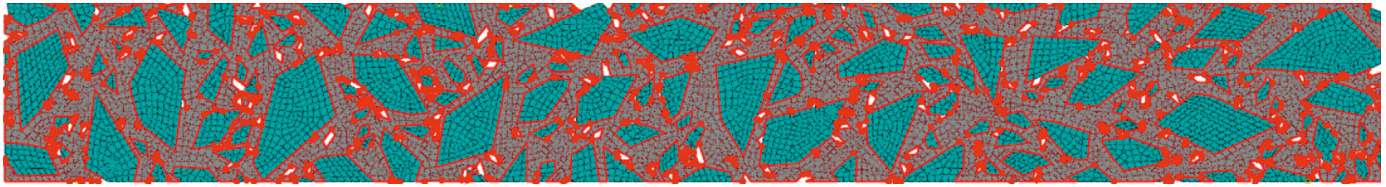

FIGURE 6: Final FEM modelling for the asphalt mixtures.

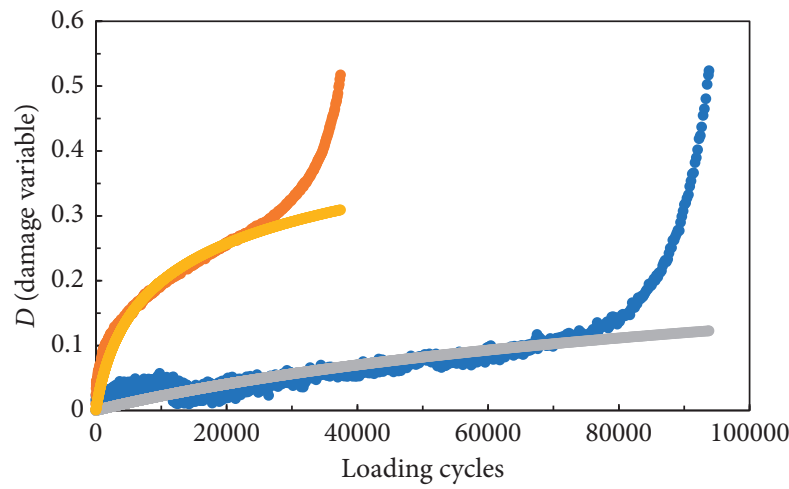

- $700 \mu \varepsilon$-laboratory test $\quad 700 \mu \varepsilon$-fitting

- $1000 \mu \varepsilon$-laboratory test $\quad$. $1000 \mu \varepsilon$-fitting

(a)

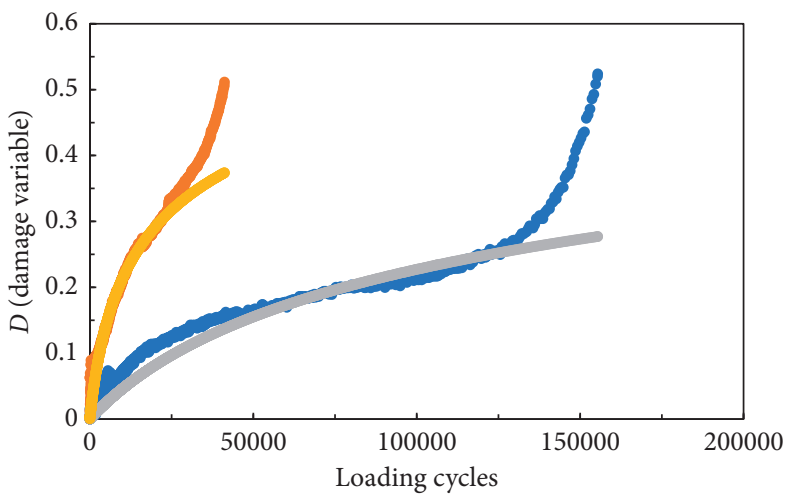

- $700 \mu \varepsilon$-laboratory test $\quad 700 \mu \varepsilon$-fitting

- $1000 \mu \varepsilon$-laboratory test $\quad 1000 \mu \varepsilon$-fitting

(b)

Figure 7: Continued. 


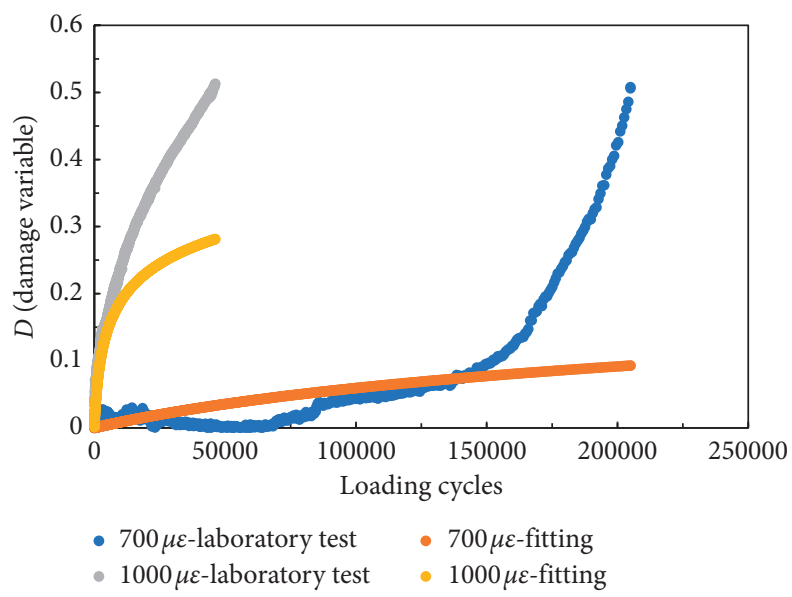

(c)

FIgURE 7: Fatigue performance prediction of the asphalt mortar at $5^{\circ} \mathrm{C}$ : (a) low asphalt content; (b) moderate asphalt content; (c) high asphalt content.

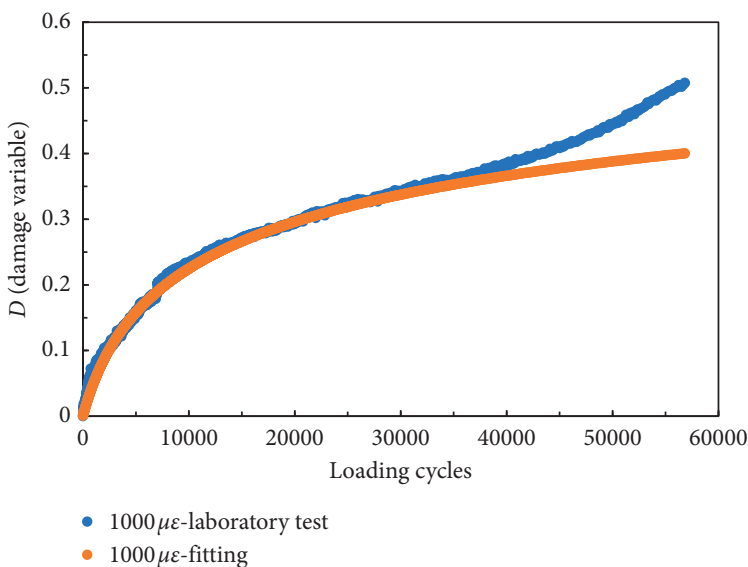

(a)

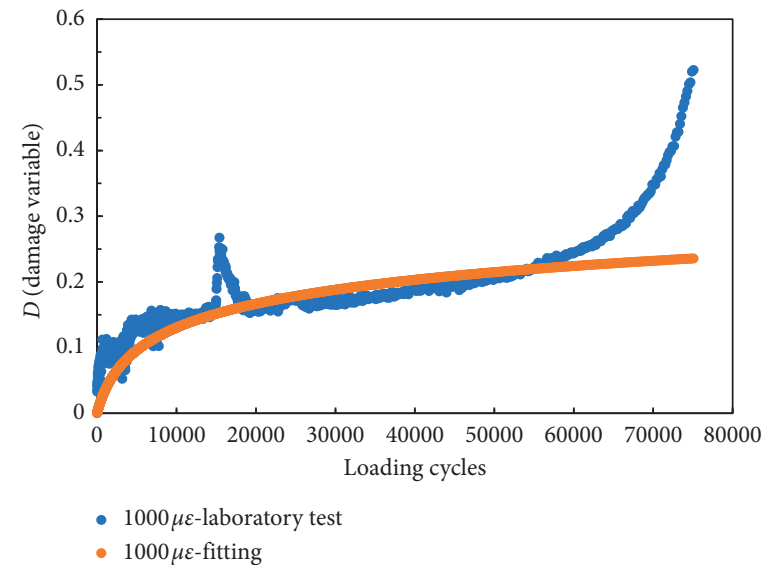

(b)

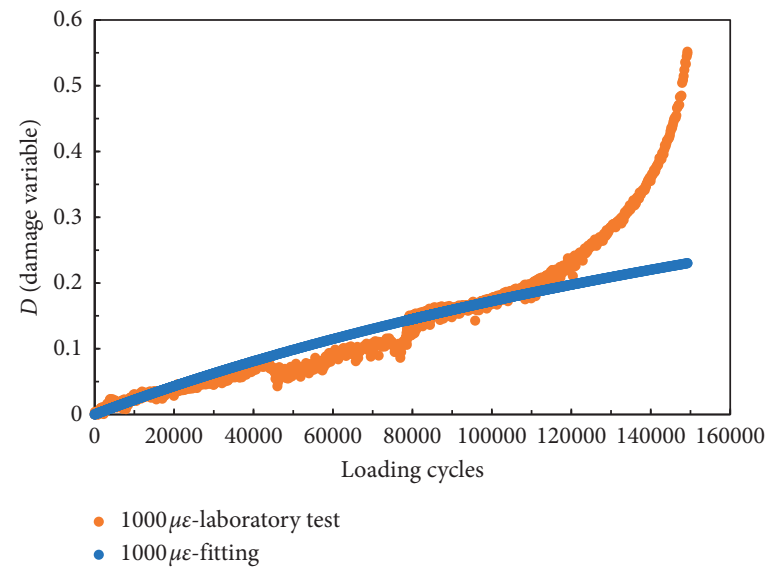

(c)

FIGURE 8: Fatigue performance prediction of the asphalt mortar at $10^{\circ} \mathrm{C}$ : (a) low asphalt content; (b) moderate asphalt content; (c) high asphalt content.

temperature means the beam structure is more similar to the elastic solid. So, the performance of the mortar at the high asphalt content was slightly different from the low and moderate ones. With the worst conditions (highest asphalt content at the lowest temperature), the mortar would become stiffer than others. So, the bending stiffness 
TABLE 4: Fitting parameters of the proposed damage evolution model under different conditions.

\begin{tabular}{|c|c|c|c|c|}
\hline Asphalt content (\%) & Temperature $\left({ }^{\circ} \mathrm{C}\right)$ & Loading strain $(\mu \varepsilon)$ & $A$ & $p$ \\
\hline \multirow{3}{*}{ Low } & 5 & 700 & $6.1 e-5$ & 9 \\
\hline & 5 & 1000 & $6.1 e-5$ & 9 \\
\hline & 10 & 1000 & $6 e-5$ & 7 \\
\hline \multirow{3}{*}{ Moderate } & 5 & 700 & $4.7 e-5$ & 6.1 \\
\hline & 5 & 1000 & $4.7 e-5$ & 6.1 \\
\hline & 10 & 1000 & $4.6 e-5$ & 15.7 \\
\hline \multirow{3}{*}{ High } & 5 & 700 & $9.3 e-5$ & 13 \\
\hline & 5 & 1000 & $9.3 e-5$ & 13 \\
\hline & 10 & 1000 & $2.3 e-6$ & 3 \\
\hline
\end{tabular}
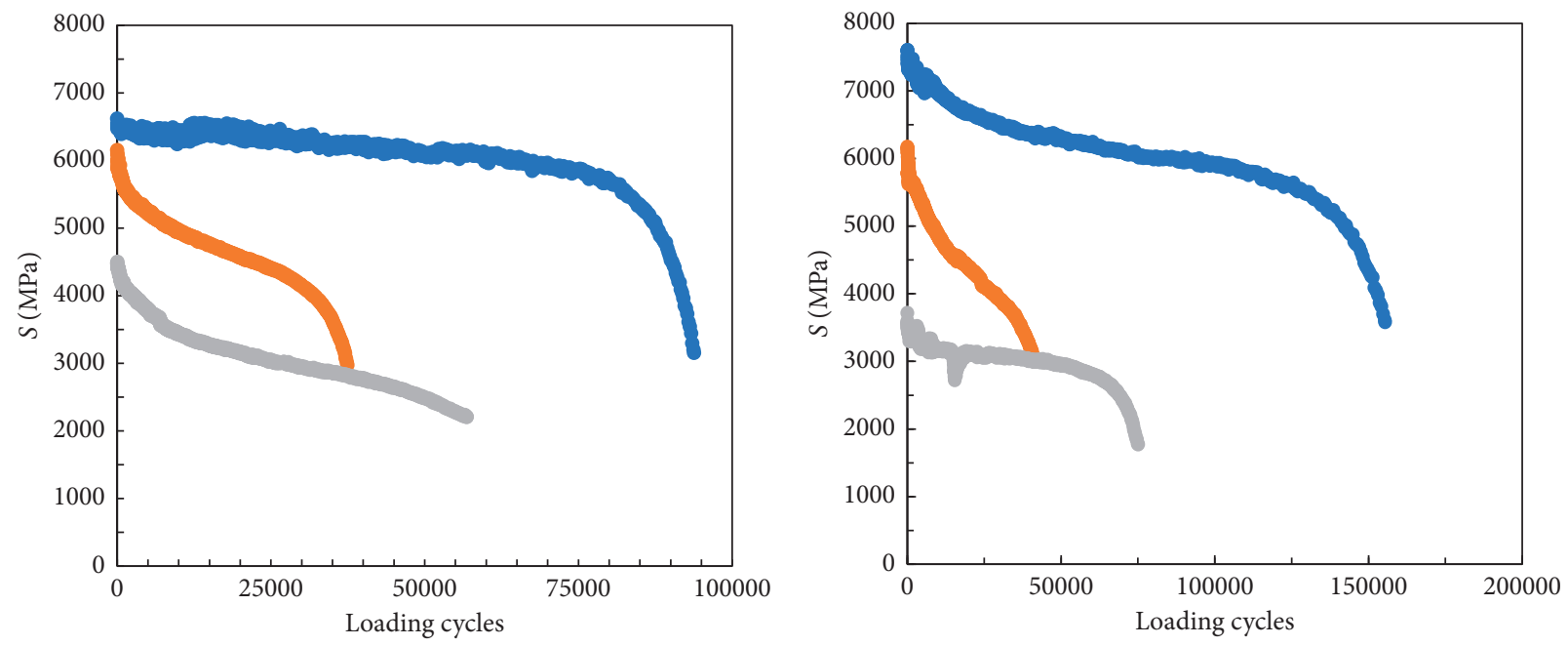

- $5^{\circ} \mathrm{C}, 700 \mu \varepsilon$

$5^{\circ} \mathrm{C}, 1000 \mu \varepsilon$

$10^{\circ} \mathrm{C}, 1000 \mu \varepsilon$
- $5^{\circ} \mathrm{C}, 700 \mu \varepsilon$

- $5^{\circ} \mathrm{C}, 1000 \mu \varepsilon$

- $10^{\circ} \mathrm{C}, 1000 \mu \varepsilon$

(a)

(b)

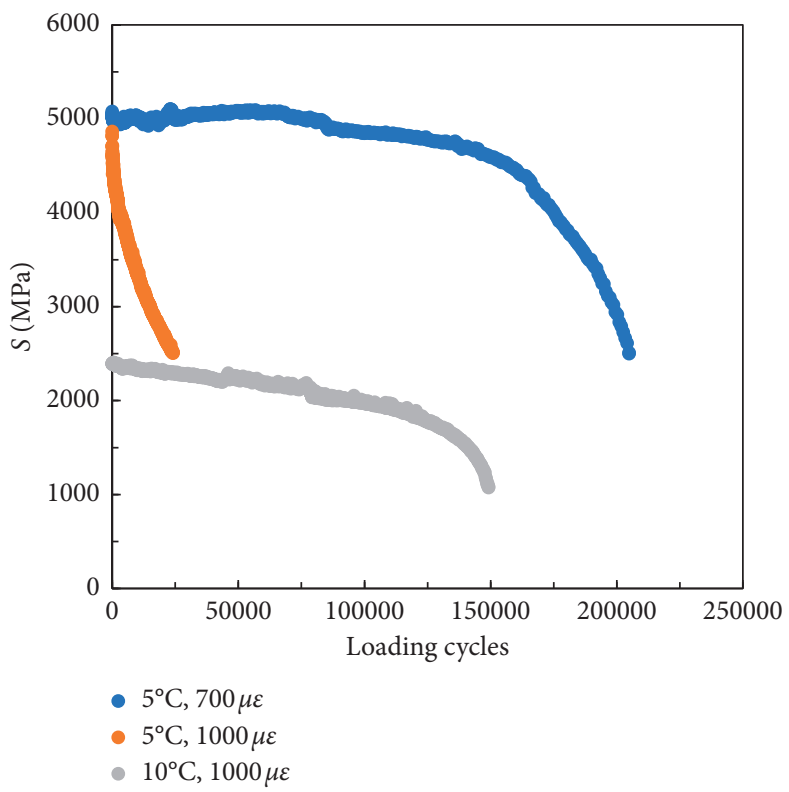

(c)

FiguRE 9: Influences of the temperatures and strain levels on the fatigue performance of asphalt mortar: (a) low asphalt content; (b) moderate asphalt content; (c) high asphalt content. 


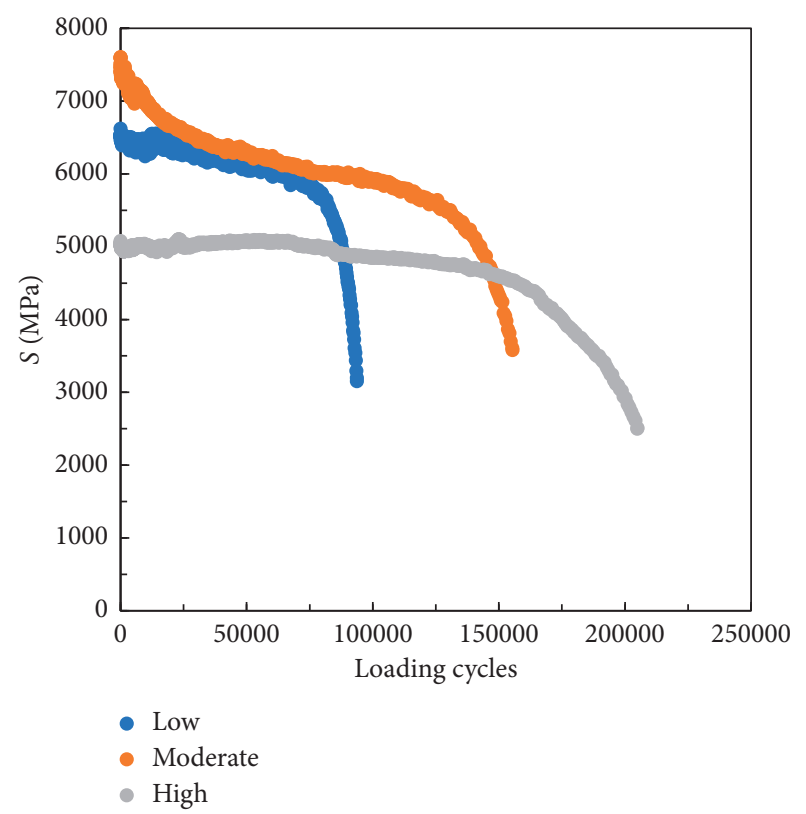

(a)

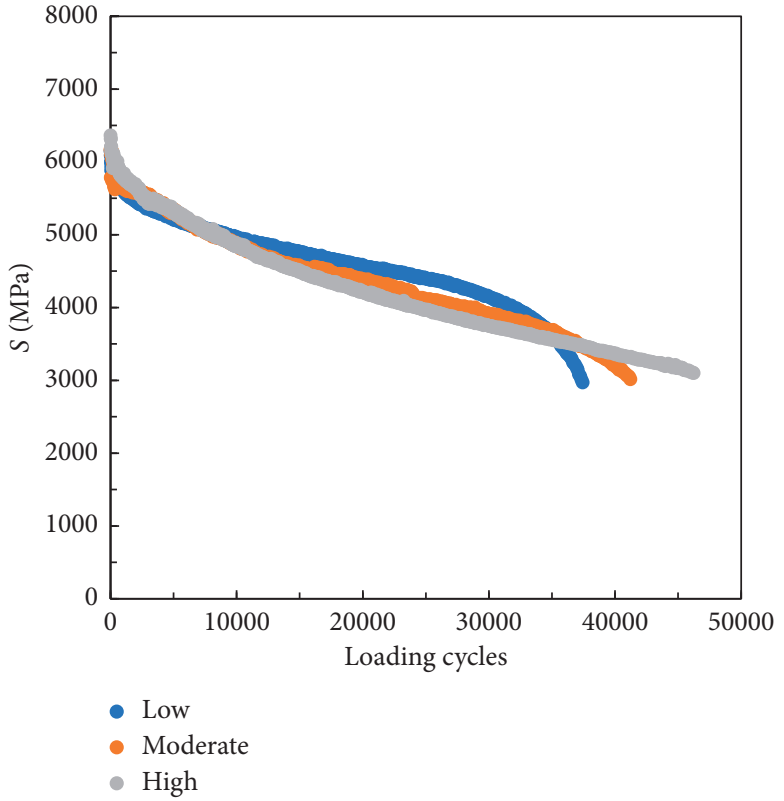

(b)

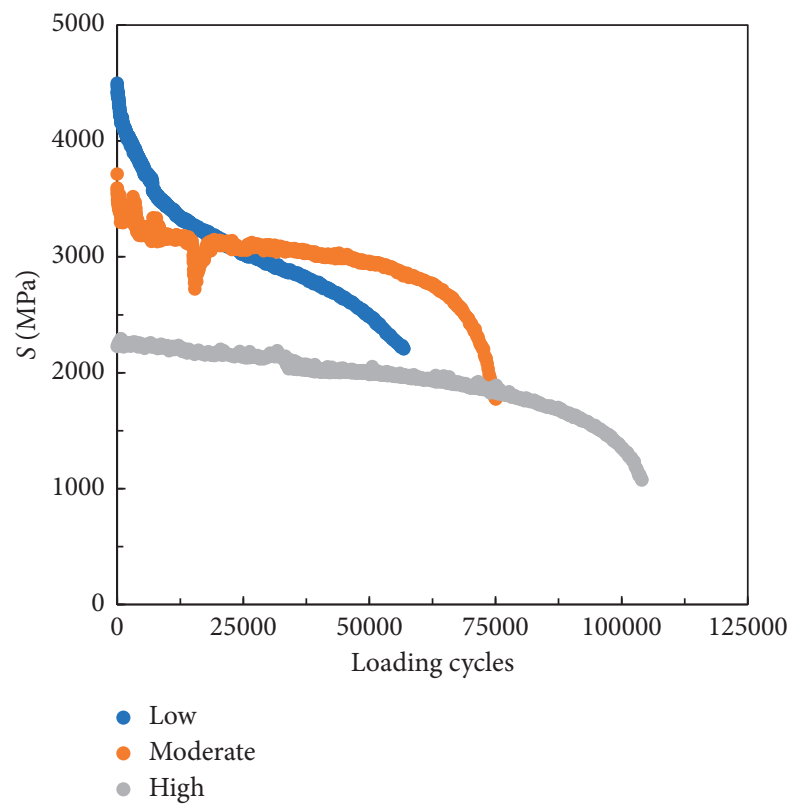

(c)

Figure 10: Influences of the asphalt content on the fatigue performance of asphalt mortar: (a) $5^{\circ} \mathrm{C}, 700 \mu \varepsilon$; (b) $5^{\circ} \mathrm{C}, 1000 \mu \varepsilon$; (c) $10^{\circ} \mathrm{C}, 1000 \mu \varepsilon$.

modulus (S) of the $5^{\circ} \mathrm{C}, 1000 \mu \varepsilon$ was a litter larger than the other two at the beginning. Under the largest strain level of $1000 \mu \varepsilon$, it would decline sharply at the fastest speed which could be seen in Figure 9(c).

Figure 10 shows the influences of the asphalt content on the fatigue performance of asphalt mortar. As shown, the asphalt content has a positive effect on the fatigue performance of the asphalt mortar despite the loading conditions. Compared to the asphalt mixtures, although there is no coarse aggregate skeleton, the curve trends of the mortar also go through three stages known as starting stage, stable stage, and unstable stage. It is a rough verification of the assumption that the damage evolution mainly processed within the mortar and the aggregates only form the skeleton in mixtures. From the perspective of mechanical calculation, these coarse aggregates can be regarded as boundary conditions directly.

4.2. Verification of the FEM Implementation of the Fatigue Damage Model. The proposed fatigue damage model was implemented into the ABAQUS software via UMAT user subroutine. The FE model of the asphalt mortar was constructed as described in Section 3.4. In the real test, 


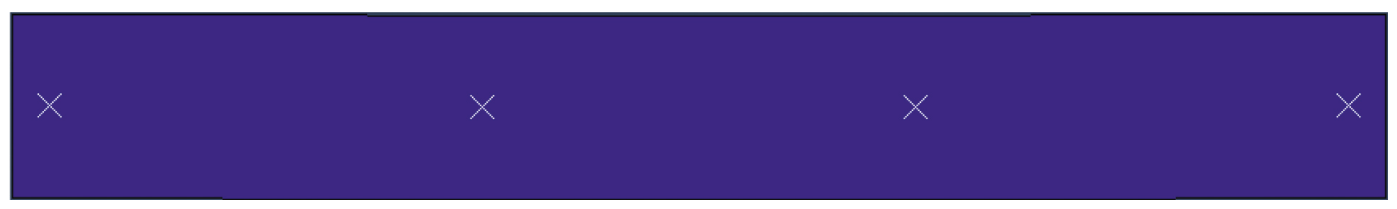

(a)

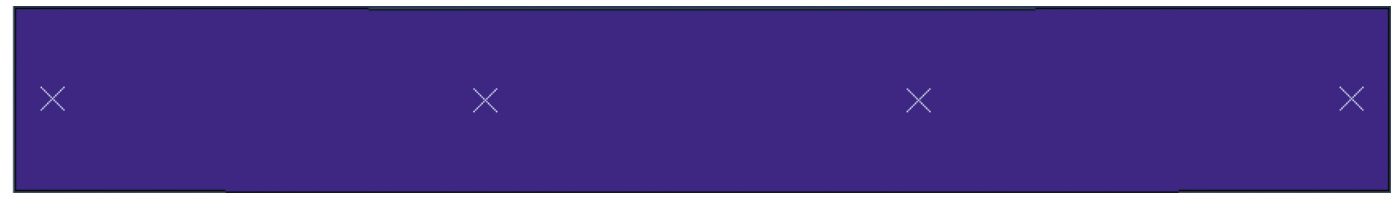

(b)

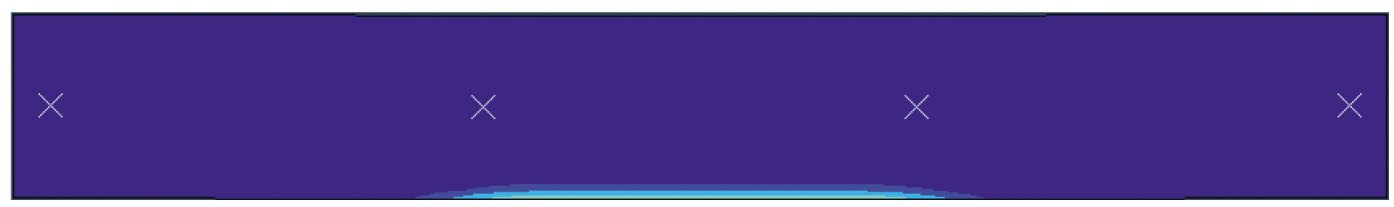

(c)

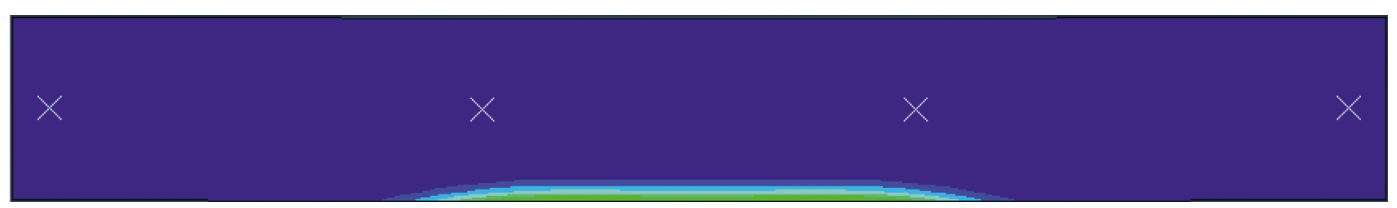

(d)

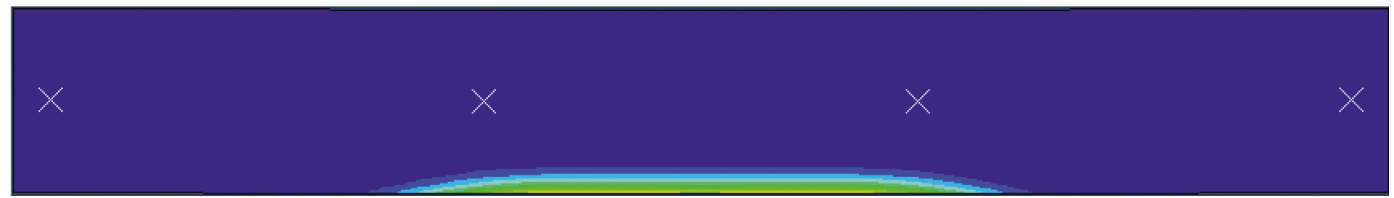

(e)

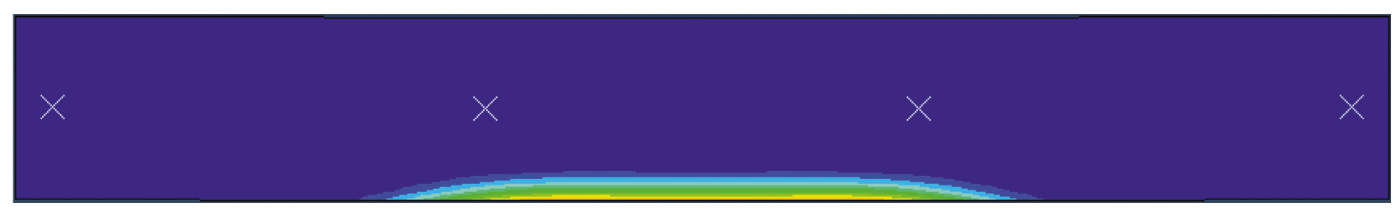

(f)

Figure 11: Damage evolution of asphalt mortar with load cycles. (a) Load cycles $N=200, D_{\max }=2.041 e-4$; (b) load cycles $N=2000, D_{\max }=$ $5.492 e-3$; (c) load cycles $N=20000, D_{\max }=5.278 e-2$; (c) load cycles $N=40000, D_{\max }=8.840 e-2 ;(\mathrm{e})$ load cycles $N=60000, D_{\max }=$ $1.137 e-1$; (f) load cycles $N=77600, D_{\max }=1.422 e-1$.

maximum deflection and peak load of each cycle were recorded. Correspondingly, vertical displacement of the beam centre and the contact force between clamp A and the sample were recorded in the simulations. Additionally, the damage variable in the UMAT subroutine was also outputted.

The four-point bending beam fatigue tests of the asphalt mortar specimens with different asphalt contents, different temperatures, and different loading strains as described previously were simulated. The simulation results of the sample with moderate asphalt content under test condition of $5^{\circ} \mathrm{C}$ and $700 \mu \varepsilon$ are shown in Figure 11.

It can be seen from Figure 11 that in the whole fatigue evolution process of the asphalt mortar sample, the damaged area slightly increased, showing an upward expansion trend. The main damage area was concentrated between clamp A on the bottom of the sample, and the damage variables were substantially the same at the same height. This is because the middle part of the sample was in a purely bending state and the tensile strain of the sample was the same at the same height. In other parts of the sample, the specimen was subjected to compressive stress, or the tensile strain generated was very small, which was negligible compared with the area where the damage had occurred. The damage area was relatively small, which accounted for about $1 / 30$ of the area of the sample.

The load cycles of the simulations were recorded, and the calculated damage variables at the end of simulations were compared with those of the tests. The results are summarized in Table 5. It indicated that the FE implementation can accurately characterize the mechanical behavior of the proposed fatigue model. 
TABLE 5: Comparison between simulated damage variable and measured damage variable under different test conditions.

\begin{tabular}{|c|c|c|c|c|}
\hline Asphalt content (\%) & Temperature $\left({ }^{\circ} \mathrm{C}\right)$ & Loading strain $(\mu \varepsilon)$ & Simulated damage & Measured damage \\
\hline \multirow{3}{*}{4.3} & 5 & 700 & 0.13 & 0.132 \\
\hline & 5 & 1000 & 0.31 & 0.307 \\
\hline & 10 & 1000 & 0.42 & 0.39 \\
\hline \multirow{3}{*}{4.8} & 5 & 700 & 0.23 & 0.282 \\
\hline & 5 & 1000 & 0.38 & 0.357 \\
\hline & 10 & 1000 & 0.23 & 0.24 \\
\hline \multirow{3}{*}{5.5} & 5 & 700 & 0.09 & 0.098 \\
\hline & 5 & 1000 & 0.18 & 0.173 \\
\hline & 10 & 1000 & 0.27 & 0.22 \\
\hline
\end{tabular}

4.3. Fatigue Performance Predictions of the Asphalt Mixture. The fatigue damage evolution of the asphalt mixtures was analyzed further based on the verified FE implementation of the proposed fatigue model.

A four-point bending fatigue test for asphalt mixture was conducted under the condition of $5^{\circ} \mathrm{C}, 700 \mu \varepsilon$ and moderate asphalt content. The void ratio of the sample is $4 \%$. A virtual test with the same void ratio was constructed using random packing method described in Section 3.4. A fatigue test was simulated under the same test condition. The peak load and maximum deflection were outputted, and the bending stiffness modulus was calculated using equations (1)-(3). As shown in Figure 12, the proposed FE model can well characterize the fatigue performance of the asphalt mixture in the first two stages.

Three virtual mixture samples with $0 \% \mathrm{VV}, 4 \% \mathrm{VV}$, and $8 \% \mathrm{VV}$ were constructed. Fatigue test simulations were conducted. Figure 13 shows the details of the virtual simulations at the 100000 th loading cycle. As shown, the voids content plays a negative role in the fatigue performance of the asphalt mixtures. The maximum damage variables are $0.2042,0.2232$, and 0.2755 for the $0 \% \mathrm{VV}, 4 \%$ $\mathrm{VV}$, and $8 \% \mathrm{VV}$, respectively. Since there are no voids in Figure 13(a), the maximum damage occurred in the particles' edge. Differently, when comes to Figure 13(b) and 13 (c), it is found that the boundary of the voids tend to cause damage more easily. The maximum damage always arose from the void edges. Comparing the simulation results of Figures 13(a)-13(c), it is concluded that as the void content increased, the damage evolved more sharply and the damage tended to arose from the void edges due to a stress concentration.

The reduction of the bending stiffness modulus of three virtual fatigue tests is shown in Figure 14. It can be seen that as the void ratio increased, the decay rate of the stiffness modulus increased. The difference between curves of samples with $4 \% \mathrm{VV}$ and $8 \% \mathrm{VV}$ was much larger than that between curves of samples with $0 \% \mathrm{VV}$ and $4 \% \mathrm{VV}$. It indicated that the damage accumulation increased nonlinearly when the void ratio increased linearly. The void ratio had a significant influence on the fatigue performance of asphalt mixture.

\section{Conclusions}

This paper proposed a fatigue damage evolution model of the asphalt mortar based on the four-point fatigue

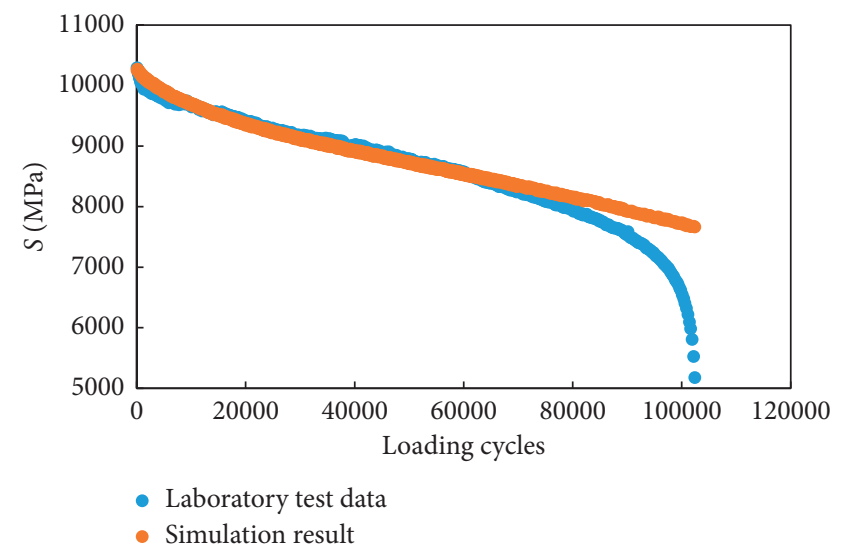

FIgURE 12: Comparison between simulated damage variable and measured damage variable of asphalt mixture.

bending tests. By fitting the laboratory results, the proposed model was verified, and the related parameters were determined under different loading conditions. By importing the damage model into FEM simulation, the major influences on the fatigue damage of the asphalt mixtures were analyzed further. The main conclusions drawn from the study are as follows.

The load strain has a negative effect on the bending stiffness modulus of asphalt mortar while the temperature and asphalt content have a positive one. When the asphalt content is fixed, decreasing the load strain is more effective than increasing the temperatures in improving the fatigue life of the mortar. Since the environmental temperature is uncontrollable during the pavement usage, avoiding the heavy traffic is an effective means to maintain the pavement permanent performance.

The proposed damage model was established based on the continuum mechanics. It characterized the performance of the tiny point within the whole structure which can represent the micromaterial property rather than the macrostructure. By fitting the model curves with the realistic, it has been validated that the proposed methods can well characterize the fatigue life of the asphalt mortar in the first two stages.

The damage evolution curves of the mortar are similar with the asphalt mixtures. It is a rough verification of the assumption that the damage evolution mainly processed within the mortar and the coarse aggregates only form the 


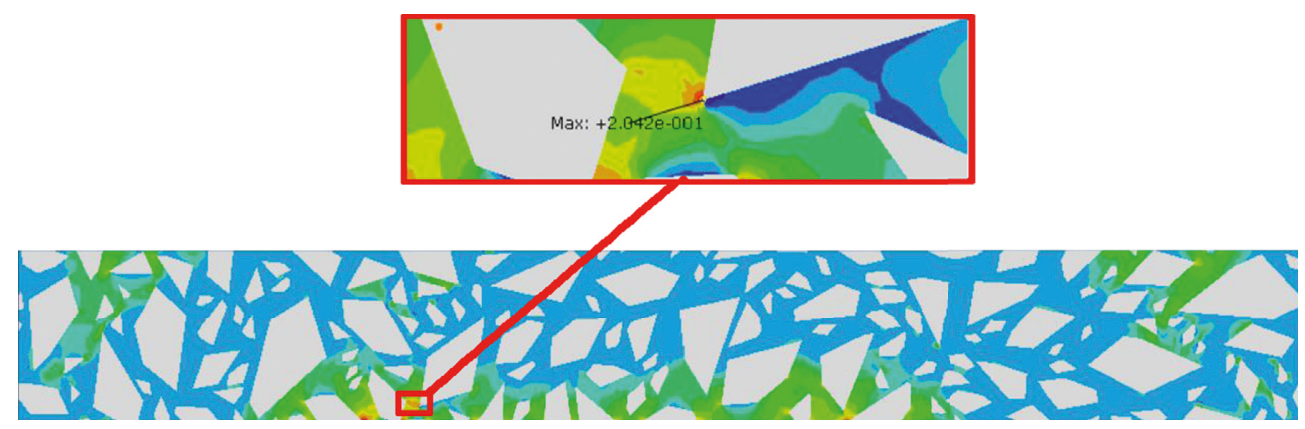

(a)

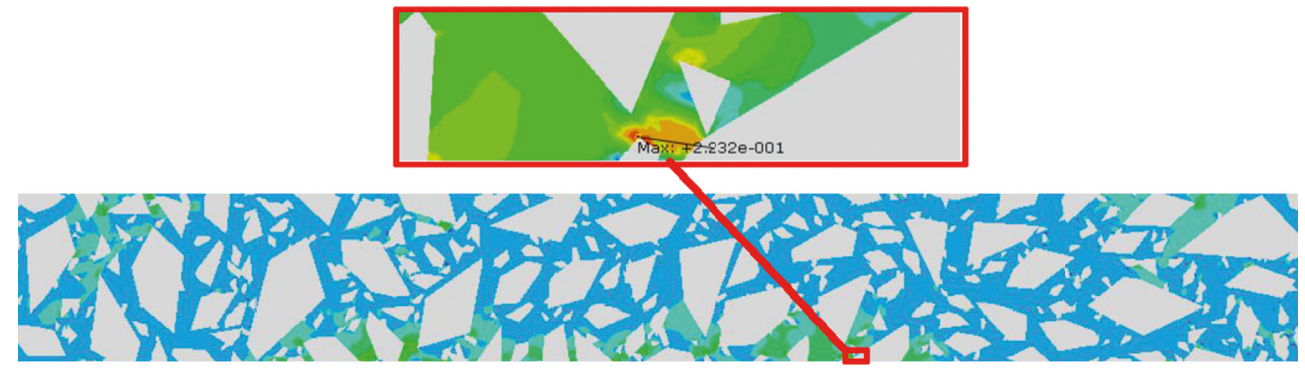

(b)

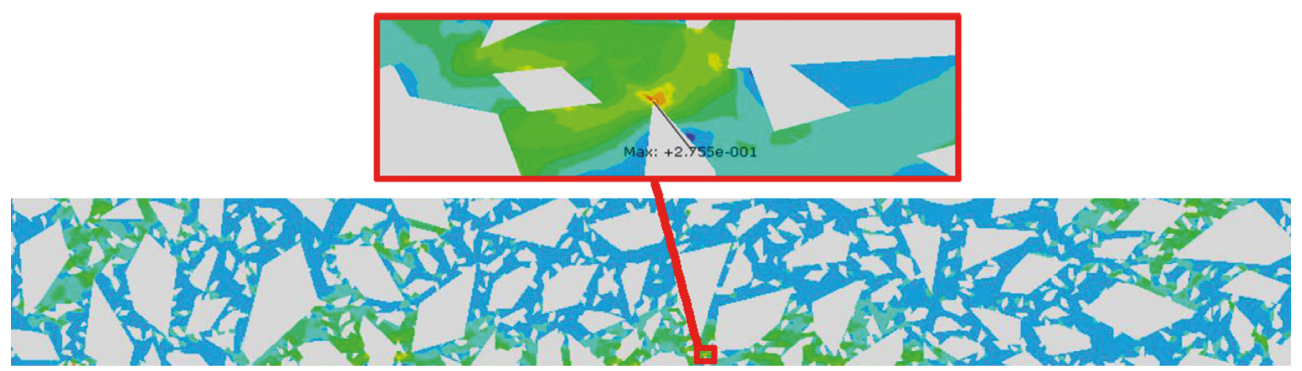

(c)

FIGURE 13: Influences of the voids on the fatigue damage of asphalt mixtures: (a) $0 \% \mathrm{VV}$; (b) $4 \% \mathrm{VV}$; (c) $8 \%$ VV.

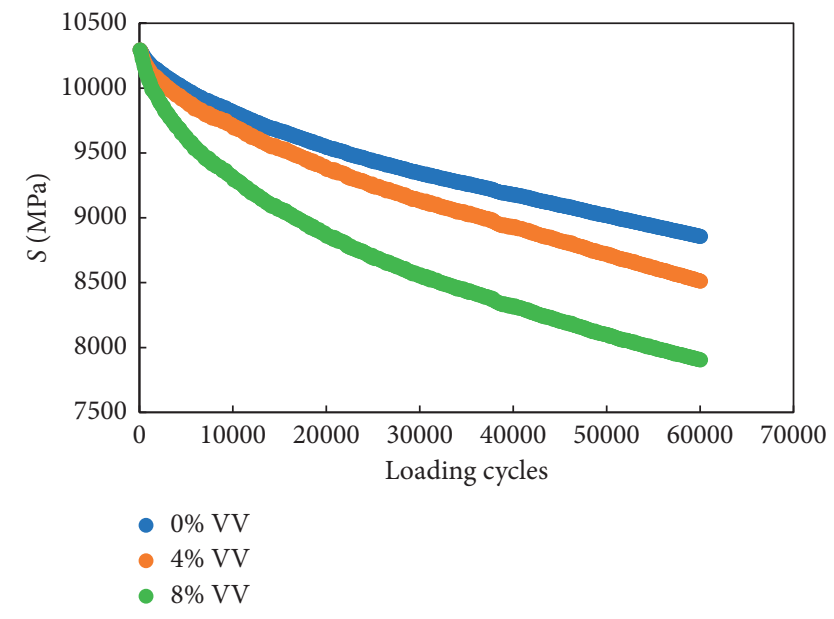

FIGURE 14: Bending stiffness modulus of virtual asphalt mixture samples with different air void ratios.

skeleton in mixtures serving as boundary conditions. Through the FEM simulation, it shows that the damage always arose from the void edges firstly, and as the void contents increased, the damage grew more sharply. By comparing the simulation results of virtual samples with different void ratios, it indicates that the damage accumulation increased nonlinearly when the void ratio increased linearly. The void ratio had a significant negative influence on the fatigue performance of asphalt mixture.

\section{Data Availability}

The FEM simulation data and laboratory test data used to support the findings of this study are available from the corresponding author upon request.

\section{Conflicts of Interest}

The authors declare that they have no conflicts of interest regarding the publication of this article.

\section{Acknowledgments}

The study was financially supported by the Science Foundations of Nanjing Institute of Technology (YKJ201423), National Natural Science Foundation of China (51878164), 
Jiangsu Natural Science Foundation (BK20161421), Scientific Research Foundation of Graduate School of Southeast University (YBJJ 1843), and Graduate Innovation Project of Jiangsu Province (KYCX18_0147).

\section{References}

[1] E. Gasthauer, M. Mazé, J. P. Marchand, and J. Amouroux, "Characterization of asphalt fume composition by GC/MS and effect of temperature," Fuel, vol. 87, no. 7, pp. 1428-1434, 2008.

[2] W. Wang, P. Song, and Y. Miao, "Research summary of the composition characteristics and performance of mineral aggregate of asphalt mixture," Municipal Engineering Technology, vol. 26, no. 8, pp. 13-16, 2014.

[3] T. Ma, Y. Zhong, T. Tang, and X. Huang, "Design and evaluation of heat-resistant asphalt mixture for permafrost regions," International Journal of Civil Engineering, vol. 14, no. 5, pp. 339-346, 2016.

[4] G. D. Airey, A. C. Collop, S. E. Zoorob, and R. C. Elliott, “The influence of aggregate, filler and bitumen on asphalt mixture moisture damage," Construction and Building Materials, vol. 22, no. 9, pp. 2015-2024, 2008.

[5] T. Ma, X. Ding, D. Zhang, X. Huang, and J. Chen, "Experimental study of recycled asphalt concrete modified by highmodulus agent," Construction and Building Materials, vol. 128, pp. 128-135, 2016.

[6] Y. Tan, H. Zhang, H. Xu, Y. Wang, and X. Yao, "Effect of fine aggregate form, angularity and texture on the viscoelastic properties of asphalt mortar," Asphalt Pavements, vol. 1-2, no. 1, pp. 637-648, 2014.

[7] M. R. M. Hasan, M. O. Hamzah, M. V. D. Ven, and J. Voskuilen, "Disruption of air voids continuity based on permeability loss due to mortar creep," Construction and Building Materials, vol. 116, pp. 347-354, 2016.

[8] B. G. Wang, L. I. Ping, Z. Q. Zhang, and H. W. Sun, "Influence of mineral powder on aging properties of asphalt mortar," Journal of Chang'an University (Natural Science Edition), vol. 4, pp. 6-9, 2007.

[9] F. Wang, Z. Liu, and S. Hu, "Temperature stability of compressive strength of cement asphalt mortar," ACI Materials Journal, vol. 107, no. 1, pp. 27-30, 2010.

[10] M. F. Woldekidan, M. Huurman, and A. C. Pronk, "Linear and nonlinear viscoelastic analysis of bituminous mortar," Transportation Research Record: Journal of the Transportation Research Board, vol. 2370, no. 1, pp. 53-62, 2013.

[11] S. G. Hu, T. Wang, F. Z. Wang, Z. C. Liu, T. Gao, and J. Z. Zou, "Freezing and thawing resistance of cement asphalt mortar," Key Engineering Materials, vol. 400-402, pp. 163-167, 2009.

[12] P. Cundall, "A computer model for simulating progressive large scale movement in block rock systems," in Proceedings of International Symposium. Fracture, ISRM, pp. 11-8, Nancy, France, September 1971.

[13] S. Kobayashi, S. I. Oh, T. Altan, and A. Chaudhary, "Metal forming and the finite-element method," Journal of Materials Shaping Technology, vol. 8, no. 1, p. 65, 1990.

[14] J. Zhang, J. Peng, J. Zhang, and Y. Yao, "Characterization of stress and moisture-dependent resilient behaviour for compacted clays in South China," Road Materials and Pavement Design, pp. 1-14, 2018.

[15] J. H. Zhang, J. Li, Y. S. Yao, J. Zheng, and F. Gu, "Geometric anisotropy modeling and shear behavior evaluation of graded crushed rocks," Construction and Building Materials, vol. 183, pp. 346-355, 2018.

[16] S. Y. Zhu, Q. Fu, C. B. Cai, and P. D. Spanos, "Damage evolution and dynamic response of cement asphalt mortar layer of slab track under vehicle dynamic load," Science China Technological Sciences, vol. 57, no. 10, pp. 1883-1894, 2014.

[17] P. Wang, H. Xu, R. Chen, J. Xu, and X. Zeng, "Effect of cement asphalt mortar debonding on dynamic properties of CRTS II slab ballastless track," Advances in Materials Science and Engineering, vol. 2014, Article ID 769248, 6 pages, 2014.

[18] X. Ding, T. Ma, and W. Gao, "Morphological characterization and mechanical analysis for coarse aggregate skeleton of asphalt mixture based on discrete-element modeling," Construction and Building Materials, vol. 154, pp. 1048-1061, 2017.

[19] W. P. Sun, Y. R. Kim, and R. A. Schapery, "A viscoelastic continuum damage model and its application to uniaxial behavior of asphalt concrete," Mechanics of Materials, vol. 24, no. 4, pp. 241-255, 1996.

[20] H. J. Lee and Y. R. Kim, "Viscoelastic continuum damage model of asphalt concrete with healing," Journal of Engineering Mechanics, vol. 124, no. 11, pp. 1224-1232, 1998.

[21] J. L. Zheng and S. T. Lu, "Nonlinear fatigue damage model for asphalt mixtures," China Journal of Highway and Transport, vol. 22, no. 5, pp. 21-28, 2009.

[22] Y. R. Kim, C. Baek, B. S. Underwood, V. Subramanian, M. N. Guddati, and K. Lee, "Application of viscoelastic continuum damage model based finite element analysis to predict the fatigue performance of asphalt pavements," KSCE Journal of Civil Engineering, vol. 12, no. 2, pp. 109-120, 2008.

[23] B. Underwood, C. Baek, and Y. Kim, "Simplified viscoelastic continuum damage model as platform for asphalt concrete fatigue analysis," Transportation Research Record Journal of the Transportation Research Board, vol. 2296, no. 1, pp. 36-45, 2015.

[24] T. Boukharouba, M. Elboujdaini, and G. Pluvinage, Damage and Fracture Mechanics: Failure Analysis of Engineering Materials and Structures, Springer Science + Business Media, Berlin, Germany, 2009.

[25] J. E. Kliewer, H. Zeng, and T. S. Vinson, "Aging and lowtemperature cracking of asphalt concrete mixture," Journal of Cold Regions Engineering, vol. 10, no. 3, pp. 134-148, 1996.

[26] Ministry of Transport of the People's Republic of China, Technical Specification for Construction of Highway Asphalt Pavements, China Communications Press, Beijing, China, 2004.

[27] Ministry of Transport of the People's Republic of China, Standard Test Methods of Bitumen and Bituminous Mixtures for Highway Engineering, China Communications Press, Beijing, China, 2011. 


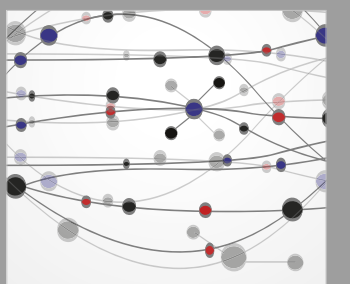

The Scientific World Journal
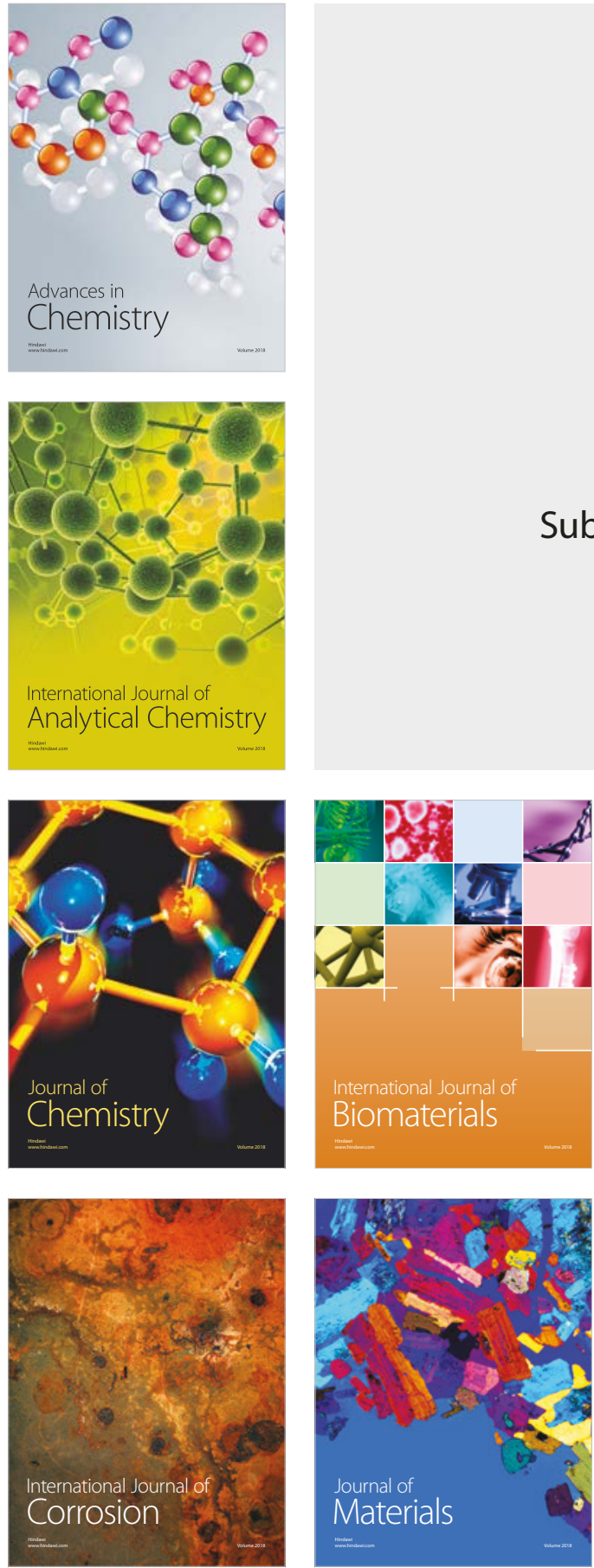

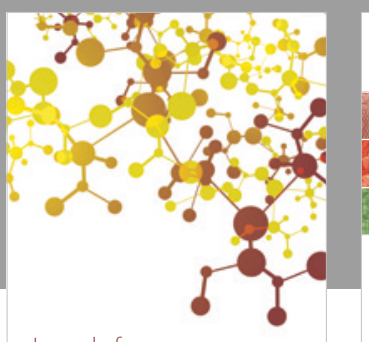

Journal of

Applied Chemistry
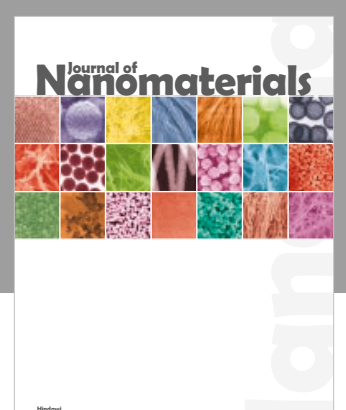

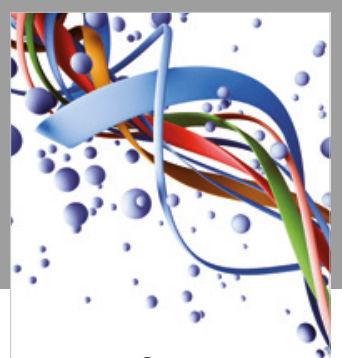

Scientifica

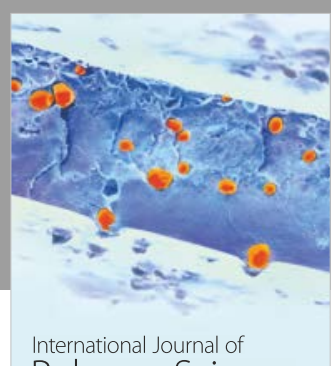

Polymer Science

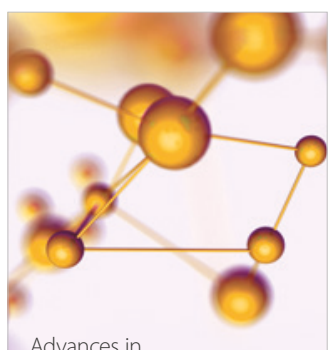

Physical Chemistry
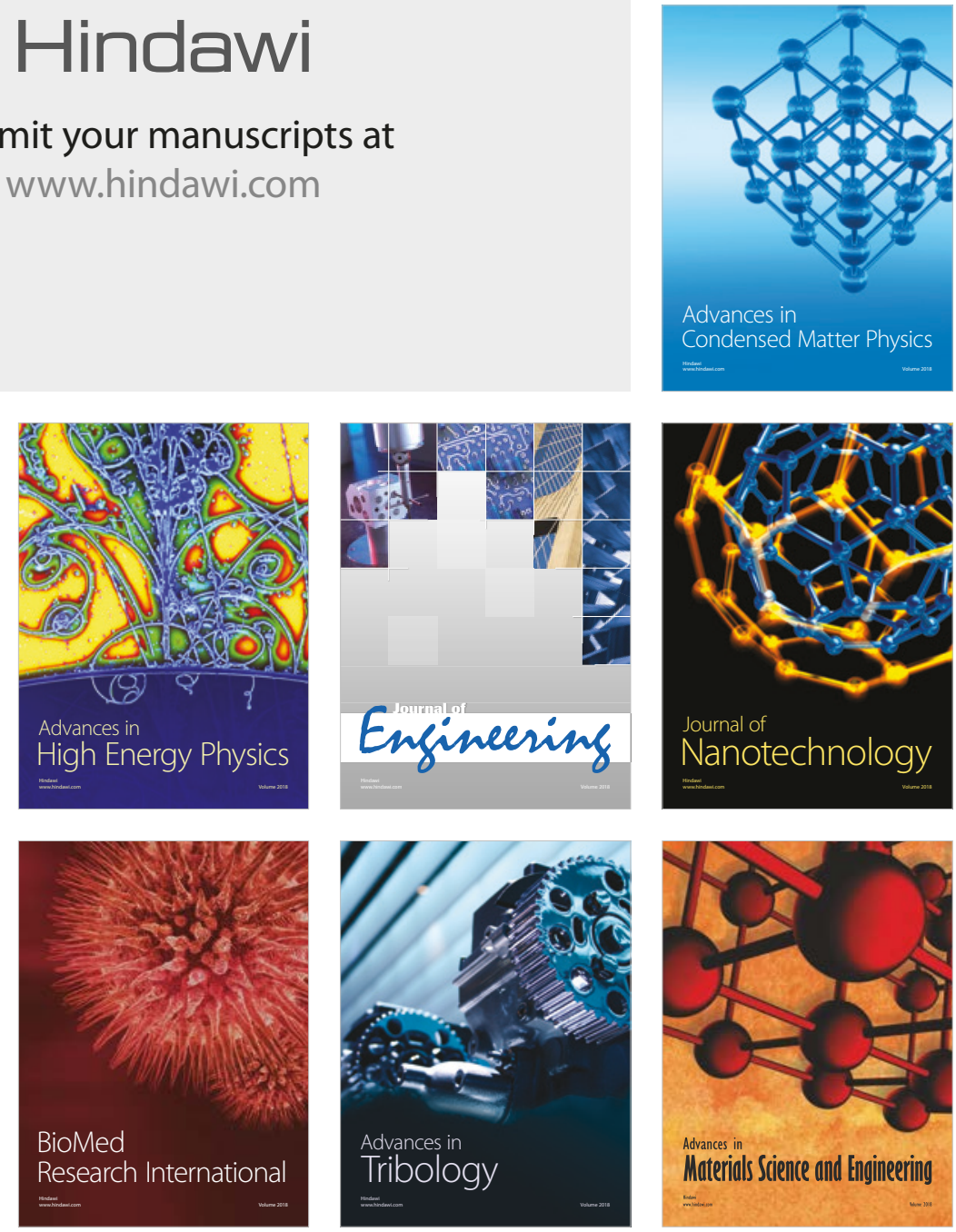